\title{
Adoption of Sharing and Reuse of Open Resources by Educators in Higher Education Institutions in the Netherlands: A Qualitative Research of Practices, Motives, and Conditions
}

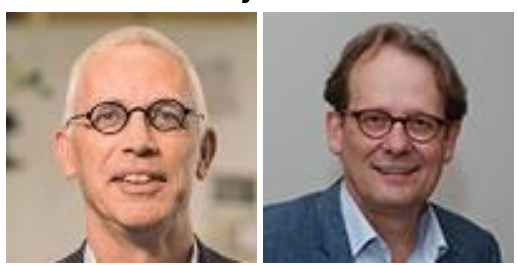

Robert Schuwer and Ben Janssen

Fontys University of Applied Sciences

\begin{abstract}
To find out what is needed to speed up the adoption of open sharing and reuse of learning materials and open online courses in publicly funded Dutch institutions of Higher Education, a qualitative research study was conducted in fall 2016. This study examined issues of willingness of educators and management, barriers and enablers of adoption, and the role of institutional and national policy in the adoption of open sharing and reuse of learning materials and online courses. Fifty-five stakeholders (educators, board members, and support staff) in 10 Dutch Higher Education Institutions were interviewed. The main findings of this study are: motivation for sharing and reuse of learning materials for educators and managers is directly related to the ambition to achieve better education for students; sharing and reuse of learning materials is common practice, very diverse and not open accessible for the whole world, and important barriers include lack of awareness of opportunities for open sharing and reuse and lack of time. Based on the findings from the interviews, the last section of this paper presents conclusions and recommendations regarding how Dutch institutions for Higher Education can formulate effective policies to raise awareness, organize adequate support and provide time to experiment.
\end{abstract}

Keyword: adoption of open resources, innovation, OER, Rogers' theory of innovation diffusion, Elias' notion of configuration, HE institution as innovation system, Dutch Higher Education 


\section{Introduction}

In June 2015 the Dutch Ministry of Education published its Strategic Agenda: The value of knowledge. Strategic Agenda for Higher Education and Research 2015-2025 (Ministry of Education, Culture and Science, 2015). In this agenda, the following ambitions regarding open and online education in the Netherlands are presented:

- "I call on institutes and their teaching staff to share their educational resources and to use materials from their colleagues both inside and outside their institutes."

- "I also, within this context, attach importance to the Dutch institutes' recognition of each other's MOOCs and 'Open Educational Resources'." (Ministry of Education, Culture and Science, 2015, p. 30).

Publicly funded Higher Education institutions in the Netherlands affected by these ambitions include 14 research based universities and 42 universities of applied sciences with a total of more than 700,000 students (2017) and 120,000 employees (in FTE, 2016) ${ }^{\mathrm{ii}}$.

Although the University of Delft was known for its use of OER in 2015 (van Valkenburg, Kos, \& Ouwehand, 2015), the actual state of adoption of OER by Dutch institutions for Higher Education remained unclear. Simple questions such as "can you tell me what the state of affairs is on OER and MOOCs in university X or Y?" could not be answered due to lack of data. For institutions to be able to formulate effective policies, more insight was needed into the actual state of affairs.

Therefore, in fall 2015, a first national survey was undertaken to collect data about the use and/or production of Open Educational Resources (OER) and Massive Open Online Courses (MOOCs) in Dutch Higher Education (Schuwer \& Janssen, 2016). The picture that emerged from this survey was that in 10 out of 15 research universities, 12 out of 23 universities of applied sciences, and in 4 out of 8 university medical centres, there was some form of producing and publishing of OER and MOOCs (Schuwer \& Janssen, 2016). As to the reuse of OER and/or MOOCs, in 13 universities of applied sciences, 2 university medical centres and 9 research universities, OER and/or MOOCs were being reused (Schuwer \& Janssen, 2016).

What also clearly emerged was that individual educators are the most important actors in creating, publishing and reusing open educational materials in Dutch institutions for Higher Education. They are also by far the most important catalyst in keeping materials up-to-date, guaranteeing the quality of the content, adding metadata to the learning materials, and in arranging and determining the rights and licenses to be used (Schuwer \& Janssen, 2016).

However, why they do this, how they do this, and under what conditions has remained unclear. In the Netherlands neither overall studies nor in-depth case studies examining faculty members' open and sharing practices at educational institutions were available in 2016.

In order to formulate effective policies to widen the adoption of sharing and reusing OER and open online courses at the institutional level, answers to these questions are needed. Factors and measures that influence the adoption of open learning materials in Dutch Higher Education must be analysed. This explorative study attempts to address the lack of research in this area by describing and 
interpreting practices of sharing and reusing OER and open online courses by faculty and staff in Dutch public Higher Education institutions.

The research question for this study is:

What will lead to, or is needed for widening adoption of sharing of open educational resources and open online courses and of reuse of open educational resources and open online courses by educators in publicly funded institutions of Higher Education in the Netherlands?

In this article the approach taken and the findings of this research are presented. First we will present the methodology and research design. Then we will present the findings, followed by a discussion in which we will compare our findings with those of similar international research studies. Following this, we will formulate recommendations. In the last section, conclusions are presented.

\section{Method}

In this study we have not just focused on OER as products or artefacts. Instead we have defined 'sharing and reusing OER and open online courses' as new practices, being an innovation of publicly funded Higher Education in the Netherlands. This is in line with definitions of innovation in education in OECD (2014) and Brennan et al. (2014). OECD (2014) has defined innovation as: "The implementation of a new significantly improved product (good or service) or process, a new marketing method, or a new organizational method in business practices, workplace or external relationships" (p. 22-23).

Brennan et al. (2014), in the context of research on innovation in Higher Education for the European Commission, describe innovation in education as "a new or significantly improved product, process, organizational method or an organization itself developed by or having a significant impact on the activities of a Higher Education institution and/or other Higher Education stakeholders" (p. 35).

An important characteristic of an innovation system is the central role for actors, as "the actors have a great deal to do with the policy outcomes" and "the innovation systems framework stresses the involvement of actors" (Iizuka, 2013, p. 4). This central role for actors causes the different outcomes of innovations in different organizations (Rogers, 2003).

For innovations in education, the most important actor, the decisive change agent in this innovation process of adoption of sharing and reusing OER and open online courses, is the educator (Mishra, 2017; Sloep \& Jochems, 2007).

We have used the theoretical perspectives of Rogers (2002, 2003), Elias (1978) and Brennan et al. (2014) for the design of our qualitative research and for the interpretation of the findings. According to Rogers (2003), diffusion is the process in which innovation is communicated over time through certain channels among the members of a social system:

The innovation-decision process is essentially an information-seeking and information processing activity in which an individual is motivated to reduce uncertainty about the advantages and disadvantages of the innovation. The main questions that an individual typically asks about a new idea include: "what is the innovation?", "how does it work?", "why 
does it work?", "what are the innovation consequences?" and "what will its advantages and disadvantages be in my situation?" (p. 14).

Most individuals accept and adopt the new idea "not on the basis of scientific research by experts' evidence but through the subjective evaluations of near peers who have already adopted the innovation (...). Their innovation behavior tends to be imitated by others in their system" (Rogers, 2003, p. 36). And about the process in (Rogers, 2002): "Diffusion is essentially a social process through which people talking to people to spread an innovation. The innovation-decision process is the mental process through which individual (or other decision-making unit) passes (1) from first knowledge of an innovation, (2) to forming an attitude towards the innovation, (3) to a decision to adopt or reject, (4) to implementation of the new idea, and to (5) confirmation of this decision" (p. 990). To target the bigger group and to achieve the stage of an early majority, institutional support is essential (Hall, 2005). Experiences gained with the adoption by the early adopters among educators can be used, because they are aware of and have experienced the innovative attributes of open online education to their teaching practices (Wilson \& Stacey, 2004).

To describe the social process and the network of influencing peers in more detail, we follow Elias (1978). He suggests to begin investigations by analyzing neither the aggregate actions of isolated individuals nor societies as external structures, but rather the connections among individuals and society (Elias, 1978). For this, he introduced the notion of figuration, or configuration, which he "explicitly created to overcome the confusing polarization of sociological theory in theories that places the individual above society and those who place society above the individual" (Elias \& Dunning, 1990, p. 148). As suggested by Elias, individual and society or structures do not exist separately. Structures are figurations, and can only be understood as being constituted by human beings (Elias, 1978). Through the notion of figuration, the behavior of individuals can be made understandable to themselves and in relation to one another, as "it is through interdependencies - or configurations that individuals define the self and the world, they satisfy their needs, and their thoughts and actions" (Elias, 1978, p. 121).

Nevertheless, the individual educators' adoption behavior is poorly understood when context is not taken into account. Educators' behavior and their motivations are not only internal or subjective but are embedded within a social context (Giddens, 1984; Nardi, 1996). Educators' practices with regard to OER and open online courses are always mediated and dynamically influenced by their configurations. Therefore, we have taken the view that adoption of sharing and reusing OER and open online courses at the level of the institution can be seen as the result of decisions of individual stakeholders. They experience accelerators and barriers and certain boundary conditions that have to be fulfilled to adopt the innovation. Acceptance of innovation on organizational levels and the environment may play an important role. Social influences such as: the extent to which colleagues and management have adopted the innovation; facilitation; support; stimulation; control structures; legislation; and regulations all may have an influence.

We have used the perspective from Brennan et al. (2014) to sketch out the typical configuration in which an educator operates. Brennan et al. describe a Higher Education innovation system as a set of functions, components and relations. Table 1 provides a description, derived from Brennan et al. and specified for this study. 
Table 1

Higher Education Innovation System

\begin{tabular}{lll}
\hline Functions & Components & Relations \\
\hline Education & Educators & Command / execution \\
Research & Researchers & Collaboration \\
Knowledge transfer, e.g. & Institutional actors (board & Support / facilitation \\
valorization & members / faculty managers) & Financial incentives \\
& Support staff & Non-financial incentives \\
& Students & Networking \\
\hline
\end{tabular}

Note. Breakdown of a Higher Education innovation system, derived from Brennan et al. (2014).

We have combined the concept of configuration of Elias (1978) with the model of Brennan et al. (2014) to outline the system with its various types and levels of interactions in which an educator functions. Figure 1 shows the typical configuration of an educator in the Dutch public Higher Education system. We see this system as an open system in which educators are not only linked to other individuals in their institution but also to individuals external to their institution:

- Function: education

- Components: educators, board members, faculty managers, support staff. Some educators were also researchers, but they were interviewed in their role as educator.

- Relations: no exclusions. We have focused on the practices of educators in sharing and/or using OER and open online courses in their teaching activities, their relations with colleagues (internal and external to the institution), with support staff, management and with government.

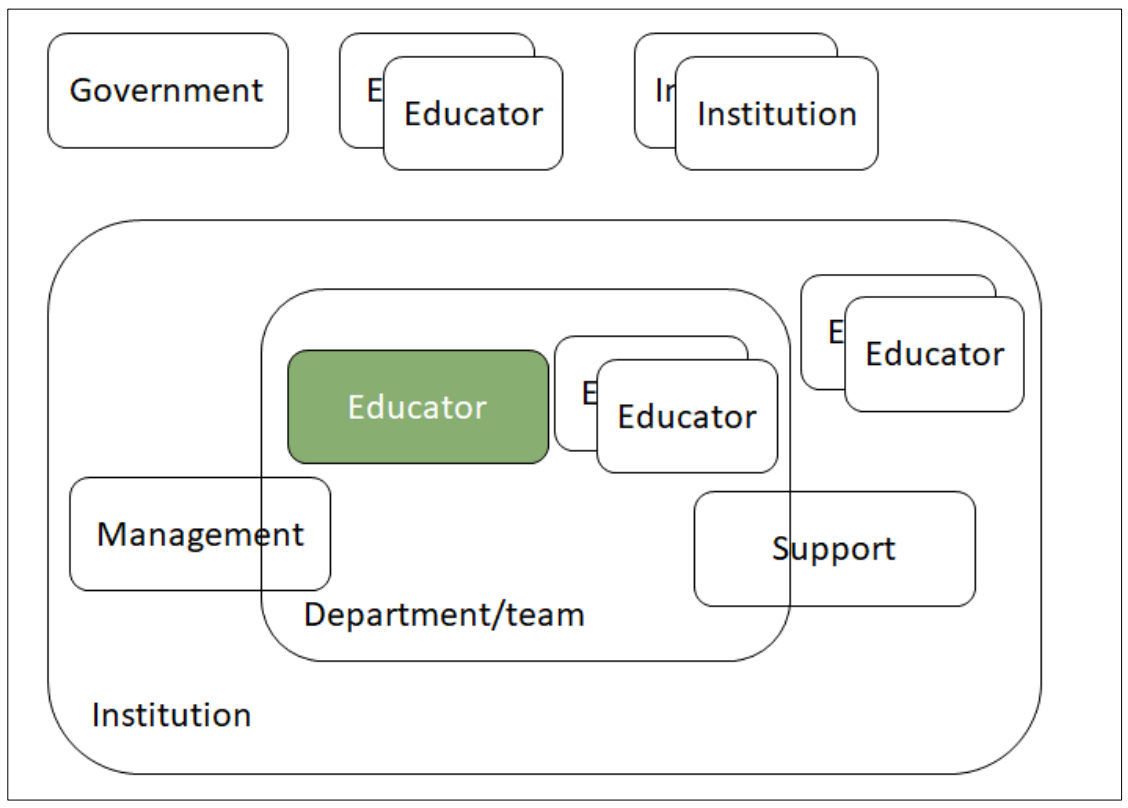

Figure 1. Configuration of an educator in the Dutch public Higher Education system. 
For this study we have opted for a qualitative approach, in which we strive to understand the many forms of innovative adoption behavior of educators. This type of research is also called the interpretative variant of qualitative research, as it focuses on issues that relate to the way in which people give meaning to their social environment and how they behave on that basis (Boeije, 2008; Bryman, 2008).

Data collection took place by semi-structured in-depth interviews with educators, supportive and managerial staff from different departments and different institutions between July 2016 and December 2016. In total, 55 interviews were conducted, each lasting 30 to 60 minutes. Six interviews were in English and the others were in Dutch. Table 2 lists the topics addressed during the interviews.

Table 2

Topics Addressed in Interviews

\begin{tabular}{|ll|}
\hline Topic (code) & Description \\
\hline Ambition & Goals to reach with education, both the results and the process. \\
Policy & Available policies on faculty or institutional level for open sharing and reuse. \\
Motives & View on open sharing and reuse and its opportunities. \\
Behavior & Motives for open sharing and reuse. \\
Accelerator & Behavior (practices) in open sharing and reuse. \\
Barrier & Factors stimulating open sharing and reuse. \\
Support & Support needed and available for open sharing and reuse. \\
Boundary condition & Factors to be arranged to realize ambitions on open sharing and reuse. \\
Influence & Influences from stakeholders on open sharing and reuse.
\end{tabular}

Note: These topics were derived from the characteristics of an innovation system and the relations described in Table 1, as well as from the topics used in the questionnaires by the OER Research Hub (de los Arcos et al, 2015). These topics were also used as codes in the analysis of the interviews.

In the interviews there was no use of a pre-defined notion of "openness". Experience from our previous survey research (Schuwer \& Janssen, 2016) and experiences derived from literature (Weller, 2014) have shown that the concept of "open" in sharing and reusing learning materials and courses can be interpreted in very different ways. For this research, the reference model in Figure 2 was constructed to describe characteristics of "open sharing and reuse." 


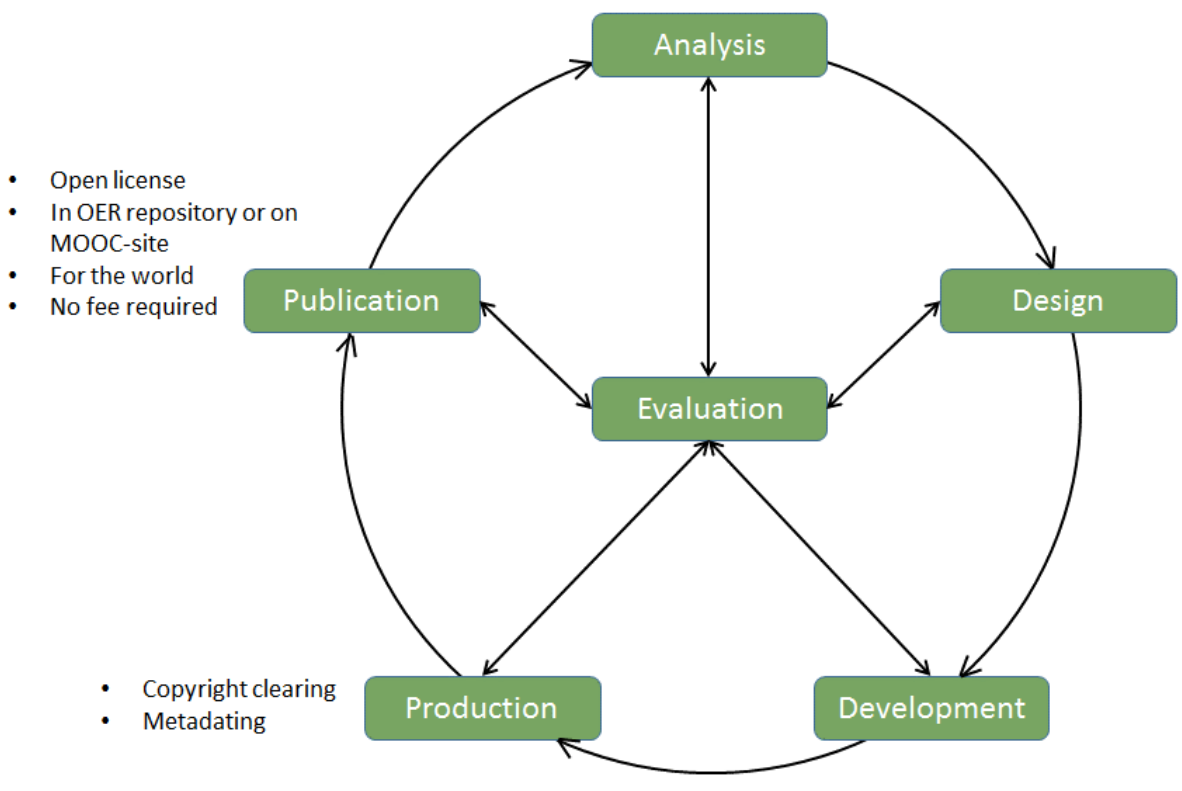

Figure 2. Model for the cycle of open sharing and reuse of learning materials and courses.

This model is an adaptation of the ADDIE Model for Instructional Design (Aldoobie, 2015). The creation, sharing and reuse of learning materials and courses (not necessarily open) is a cyclic process with successive steps of analysis, design, development, and implementation (production and publication). At every step, evaluation can be a reason to adapt the learning material, repeating the same cycle with the evaluation results as input. (Aldoobie, 2015).

When creating, sharing and reusing open educational resources and courses, the following assumptions are, in most cases implicitly, assumed by the open community, derived from the definition of OER (UNESCO / Commonwealth of Learning, 2012; Schuwer, Wilson, Van Valkenburg, \& Lane, 2010):

- When producing learning materials, copyright clearing takes place and metadata are added to the materials to make them easier to retrieve.

- Publication of educational materials is done under an open license that permits reuse and modification under certain conditions, in a repository that is accessible to anyone interested in the world. There are no fees required for (re)use of the materials.

In the interviews for our research study, this model was neither shown, nor explained to the interviewees. Instead, interviewees were asked what they considered open sharing and reuse in their day-to-day practice. During the analysis of the interviews, the opinion of the interviewee on openness was used as a starting point.

The empirical work was situated in Higher Education institutions which have previously reported involvement with initiatives on open sharing and reuse of learning resources. The population for the interviews was determined according to the following criteria: 
- Educators and faculty/institutions have experience with sharing and reuse of learning materials.

- Fields involved should be as broad as possible (social sciences, ICT and science, business).

In two research-based universities and two universities of applied sciences, interviews were conducted with board members, support staff, and per institution in two departments with educators and staff members. In four research-based universities and two universities of applied sciences individuals, educators and support staff were interviewed. Table 3 lists the distribution of the interviews within the different roles and types of institutions.

Table 3

Distribution of Interviews

Type of institution

Role of interviewee Research university University of Applied Sciences Total

\begin{tabular}{lccc}
\hline Management & 5 & 6 & 11 \\
Educator & 17 & 15 & 32 \\
Support staff & 8 & 4 & 12 \\
Total & 30 & 25 & 55 \\
\hline
\end{tabular}

All interviews were recorded, transcribed and coded using the Dedoose software (dedoose.com). The codes were based on the topics mentioned in Table 3 and were calibrated and finalized after the first five interviews. Two researchers coded the interviews. To measure the inter-rater agreement, a test generated by Dedoose, revealed a Cohen's kappa coefficient of 0.83 .

Coding of the interviews resulted in 1936 statements. In Figure 3, the distribution of the statements among the codes and the interviewees is displayed. 


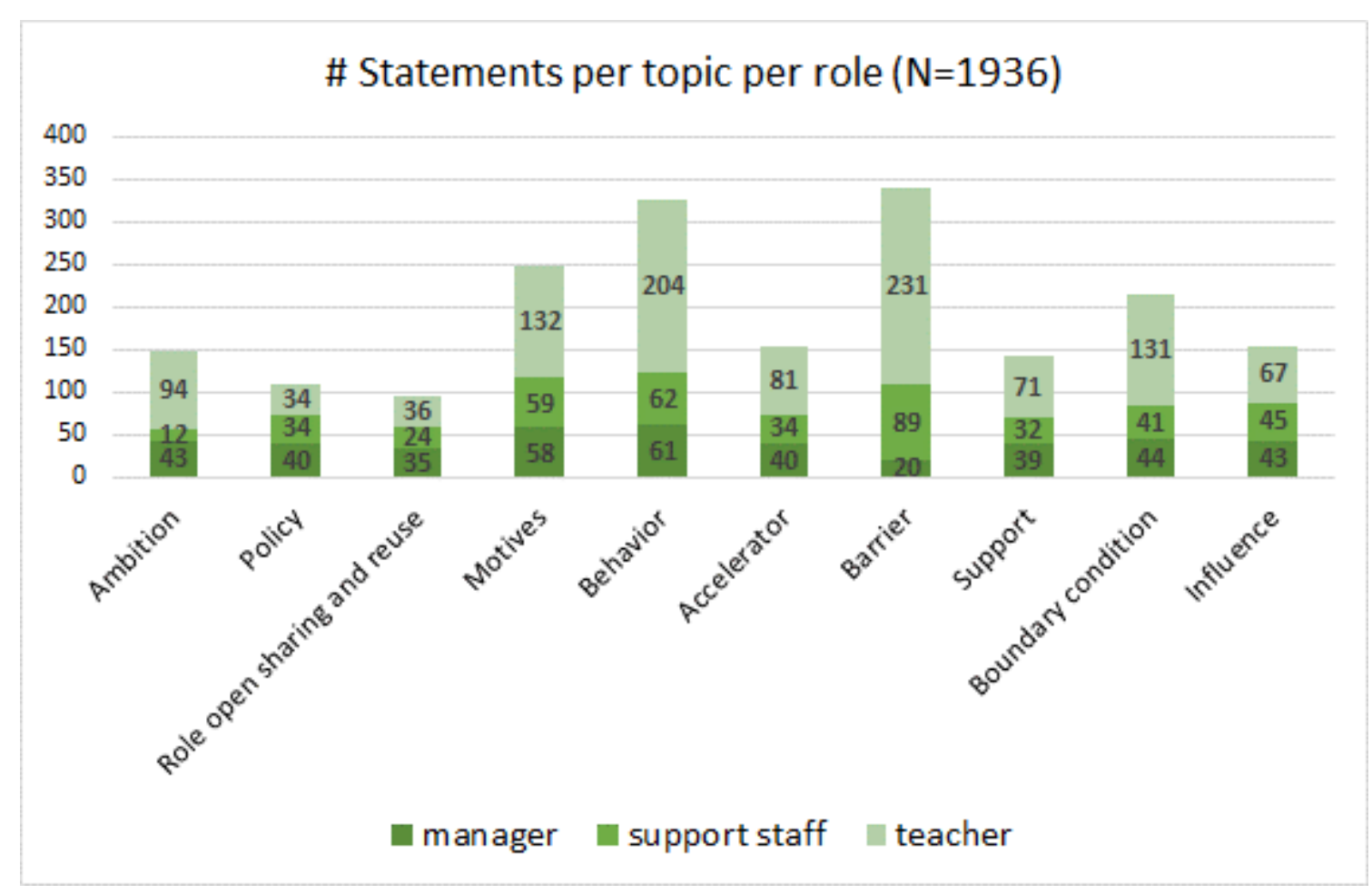

Figure 3. Distribution of statements.

\section{Ethical Issues}

Every attempt has been made to protect the identity of the participants. No demographic, sociocultural or institutional data are given which could lead to identification of participants. Before the interview, every participant was informed about the nature and purpose of their involvement, and that the interviews would be recorded and transcribed. Signed consent was obtained prior to interviews and permission was obtained to use the interview material for analysis and the report. Participants were given written assurance that information from interviews would only be used later, to ensure anonymity. Some of the participants in the study were members of the university community of which one of the authors is also a member. This probably did not affect the validity of the statements, because the interviewees were promised that their statements would be treated in a confidential and depersonalized way, and no other current issues than the ones in the questionnaire were discussed.

\section{Results}

The findings are discussed under the following headings: Practices of Sharing and Reusing OER and Open Online Courses (behavior), Motivations, Policy, Barriers and Enablers. The boundary conditions mentioned by the interviewees were the barriers to be removed and the enablers to be enforced, and are thus included in "Barriers" and "Enablers." Ambitions with education, the role of open sharing and reuse and influences are included in "motivations" and "policy."

To illustrate the findings, we have added statements from the interviews. Statements originally in Dutch, were verbatim translated into English. To enhance readability, some statements have been slightly adapted, without loss of the meaning and intention of the statement. 


\section{Practices of Sharing and Using OER and Open Online Courses}

Educators reported frequent sharing and reuse of learning materials in their practice. Support staff and management reported observation of the sharing and reuse of learning materials. In terms of openness of these practices, however, a great variety of practices of sharing and reuse of learning materials has been observed. In most cases the interviewees called these practices open sharing and reuse. Referring to the model in Figure 2, however, shared and reused learning materials

- are not always shared in modes accessible for everyone, but instead are shared with colleagues (inside or outside their team, department or institution),

- $\quad$ are often lacking an open license,

- do not always undergo copyright clearing processes, and

- are in many cases not labeled with metadata to enhance findability.

As formulated by one of the educators: "It is not the case that we keep the learning materials secret. So, everyone who asks for them can get them. But we will not make it available everywhere."

The reported technical platforms to share ranged from shared network drives and applications in The Cloud (such as Dropbox, YouTube and Slideshare), to institutional repositories, not always accessible for people outside of the institution. The previously named applications in The Cloud were also used for reuse of learning materials.

\section{Motivation}

Motivations to share and reuse learning materials mentioned included:

- Institutional gains such as marketing and exposure, reaching new target groups (e.g. professionals in the working force).

- Financial (expensive resources).

- Educational gains including: ability to support blended learning (with flipped classroom as most mentioned form), efficiency in creating learning materials, handling diversity, improving quality of education, and improving quality of learning materials.

- Personal gains including: recognition, idealistic motives and counterbalancing commercial publishers.

An educator formulated efficiency gains as "Take the basics of mathematics for example, why should we develop materials on this matter ourselves?" Another educator compared sharing in education with what is customary in research: "Sharing is common practice in research, so why not also in education?" An idealistic motivated educator expected and experienced reciprocity in sharing: "I have created the resources and if I can help someone with them, why not. What I hope is that that person will also share his information with me. This happens a lot." A manager saw opportunities in closer connections with the environment of the institution: "One of our core values is to openly share our knowledge. No barriers, and hoping that when we share openly, we are more capable to start research and educational projects together with business partners and the community.” 
In some cases, management was not aware of sharing and reuse practices within the institution or department. Managers supposed that sharing has a positive effect on quality of learning materials, but were not familiar with facts or research to prove this.

Autonomy of an educator to determine whether or not being involved in sharing and reuse of learning materials is crucial and as such recognized and acknowledged by both management and educators. This means that forcing educators to go more open is considered unfruitful by management and could even be counterproductive. A manager formulated this as "I myself believe in that having a lot of autonomy one can achieve maximal. So I find it very important. Therefore, our management team, but also our colleagues, consider autonomy for teachers very important."

\section{Policy}

In a small number of the institutions visited, it was reported that policies on open sharing and reuse are developing, aimed at supporting educators by providing them time to develop and allow for appreciation and visibility of good practices. Institutions that do not have policies surrounding open sharing and reuse suggests that they may give priority to other urgent policy issues. For management of some of the institutions studied, openness was not a goal in itself, but a means to realize other strategic goals. Therefore, they explicitly connected adoption of openness with other educational innovations such as the introduction of blended learning or the renewal of the curriculum or with policy issues like achieving more internationalization. They assumed that this approach increases the chance of success of adoption of openness.

However, for institutions in which policies of openness were in place, educators were often insufficiently aware of them. When they were aware, they did not know the content of policies very well. As one educator formulated: "Something I miss, both on the level of educators and on the central level, is a clear strategy on why we do this, what we are aiming to accomplish and how we should act. All this seems to be absent. At the moment, a lot of effort is being put into realizing more openness. So it would be motivating to know what it is we strive for."

Consequentially, many educators were uncertain about whether it was allowed or not to openly share their learning materials. Other educators, however, were not influenced by their lack of knowledge of institutional policy when practicing open sharing of their materials. In most cases the latter group was personally motivated for their sharing behavior. Educators in institutions with a clearly communicated institutional policy on openness were in general familiar with the policy, but they mentioned a lack of translation to what gains this institutional policy could bring to themselves when being involved with openness in education.

Notable is that most interviewees, both educators and management, did not mention some need of a policy for reuse of learning materials. When specifically asked, they indicated that the biggest opportunities for reuse are in introductory courses (efficiency) and in courses on subjects where the content is aging quickly (such as some topics in a computer science program). About reuse in introductory courses an educator said "Reuse has bigger advantages when you give a basic course, while for a course in the Master's phase or a more advanced course you modify the materials in line with the research associated." A manager who was confronted with fast developments in its area experienced "Whatever materials staff has prepared, fact is that these materials have a life cycle of just one year. ...The speed of progress is so fast that we in fact discourage the development of materials by 
our staff." Reuse of MOOCs was explicitly mentioned several times to create a richer offering for students.

\section{Barriers}

Next to uncertainty caused by lack of knowledge about policy, other barriers to sharing learning materials mentioned by educators included uncertainty about the value for them to share ("what's in it for me" is not clear), uncertainty about quality and copyright violations, lack of time, lack of support and lack of awareness of opportunities for openness. As one educator said: "To reach the point where we will share our learning materials openly, I think it is important to provide insights in what the benefits are for us." And another educator about the fear for copyright violations: "One has to be very careful, especially if one also stores materials. So to protect myself, if I use things of which I have doubts, I will not even try to use our own portal, because it could bring my institution into trouble."

Also mentioned by some educators is the higher value attributed to research compared to education (especially researchers in a tenure track) and lack of a safe experimentation area (e.g. no immediate negative consequences when an error is made in using copyright protected resources). An educator said about different valuing of education and research "Being an excellent researcher and being less in teaching is accepted much more than vice versa."

In the opinion of some managers, the fact that open sharing of learning materials is not common practice, as is the case with sharing of research results, was reported as an important barrier. Managers described this as an important cultural issue within their institution. Finally, absence of enablers as discussed hereunder was also formulated as a barrier by many of the interviewees.

\section{Enablers}

For educators to become (more) involved in open sharing and reuse of learning materials, the absence or minor impact of the barriers mentioned previously was an enabler. Also, stimulation by internal grants, accompanying support and a central repository to find high quality learning materials influenced the volition of educators to share in a positive way. Support is needed for IT-related issues, educational issues (pedagogy) and copyright issues. Some educators mentioned receiving feedback on openly shared materials from peers or learners as a crucial factor for them to continue sharing. To enhance adoption of open sharing and reuse, management reported preferring organic growth, with small experiments to start and enlargement on the basis of success practices.

In institutions with experience with both publishing MOOCs and publishing OER, educators and some of the management preferred involvement with MOOCs more than involvement with OER. Especially the impact on reputation of the institution and themselves and a bigger audience providing a lot of feedback were mentioned as reasons for their preference. In these institutions, to get permission and support to publish a MOOC, its added value for campus education should be made clear. Management of these institutions consider publishing MOOCs as an accelerator for adoption of open sharing and reuse of learning materials.

Finally, both management and educators reported experiencing little influence from the policy actions from national government, nor from the ambitions mentioned in the government's strategic agenda. The current national program of stimulation grants for experiments in open online education was considered to be insufficient for realizing the ambitions put forward by national government. Some 
managers however, reported valuing the program of the government because it leads to debates about openness and provides financial means for experiments.

\section{Discussion}

In the previous section, we presented our findings clustered in a number of categories. We then summarized the motivations of educators and management, the enablers and barriers, and the relevance of the context for the behavior of educators to share and reuse (open) learning materials. In this discussion, we will deduce conclusions from these findings and compare our conclusions with results from similar studies in order to come to recommendations.

The findings of the interviews are consistent with Rogers' (2003) view of a social innovation system as formulated earlier, which states that individuals evaluate an innovation using subjective evaluations of peers.

Our findings make clear that motivation for sharing and reuse for teachers and managers in the end, comes from their ambitions to achieve better education for students. This is in line with results of similar studies (Bliss, Jared Robinson, Hilton, \& Wiley, 2013; Phalachandra \& Abeywardena, 2016; Weller, de los Arcos, Farrow, Pitt, \& McAndrew, 2015).

The motivations regarding institutional gains and personal gains are also found in similar studies by Jansen, Schuwer, Teixeira, and Aydin (2015) and Truyen et al. (2011). It is notable that savings for the students was not mentioned as a motivation, although counterbalancing commercial publishers could potentially be categorized as such. This is different from similar studies by Allen and Seaman (2016) and Bliss et al. (2013).

The practices of sharing and reusing learning materials and courses as described by interviewees are very diverse, but are not always as open as the OER-community propagates. Sharing while using an open license that allows adaptation and further dissemination under certain conditions, and publishing in such a way that the resources are available for free for anyone interested is recommended. We have seen practices of sharing, not meant for the world and not always under an open license. This finding was expected and is in line with what Weller (2014) has described, and is also consistent with findings of (de los Arcos, Cannell, \& Mcllwhan, 2016; Richter \& Ehlers, 2010; Rolfe, 2017). One might say that most of the interviewees have a rather 'narrow' view of openness, and as a result on the one hand, opportunities of open sharing and reuse remain unused. On the other hand, these existing practices are a fruitful starting ground towards more openness (Czerniewicz, Deacon, Walji, \& Glover, 2017; Mishra, 2017). By referring to their own practices, the opportunities of open sharing and reuse can be more easily demonstrated.

Many educators are not familiar with the added value of OER compared to the more closed types of sharing they practice. This last finding was also reported in Allen and Seaman (2016) and de los Arcos et al. (2016). Comparing the findings with the elements on openness in Rolfe (2017), the main elements addressed in our research were Content and Institution. Awareness about direct benefits in enhancing the practice of teaching, as Rolfe formulates, is not so profoundly found in our interviews. This may be explained because the interviewees of Rolfe were involved in an OER program, thereby probably more immersed in the world of OER than the interviewees in our study. 
Almost every educator involved in sharing and reuse has indicated that he/she experiences barriers. Most mentioned barriers are lack of time and unfamiliarity with copyright. This is in line with barriers reported in (Allen \& Seaman, 2016; Cox \& Trotter, 2017; Jhangiani, Pitt, Hendricks, Key, \& Lalonde, 2016). Some barriers that are reported (especially on reuse of OER) in the surveys by Allen and Seaman (2016), Jhangiani et al. (2016), and de los Arcos et al. (2015) were less frequently named in our research. This was especially the case with locating relevant and high quality OER. A possible explanation for this difference is that in our interviews, we have taken the interviewees' perspective on openness with regard to their actual practices of sharing and reuse as starting point. As previously indicated, in many cases this was a broader perspective than OER. So, the amount of potentially suitable learning materials is larger. Some interviewees from institutions with experience in publishing MOOCs consider this broader perspective of openness a boost for adopting open sharing and reuse of OER in their institution. This finding is also reported in (Czerniewicz et al., 2017).

Another difference with the surveys by Allen and Seaman (2016), Jhangiani et al. (2016), and de los Arcos et al. (2015) is that in these surveys educators have not indicated the higher value or award given to research compared to education as an important barrier. In fact, this issue has not been mentioned at all in these surveys. An explanation for this difference might be that in these surveys, questionnaires with closed questions have been used which did not include this particular issue. In the survey that contained an open-ended question on perceived barriers (Jhangiani et al., 2016), this issue was not mentioned by participants.

To promote wide adoption of open sharing and reuse, measures to reduce these barriers are needed. Availability of support on ICT, educational issues and copyright issues are mentioned the most by educators as a necessary precondition. This is in line with similar studies (Belikov \& Bodily, 2016; Cox \& Trotter, 2017).

In the interviews, the relative autonomy of the educator regarding open sharing and reuse is widely recognized by managers, support staff and educators. Measures to promote broad adoption of open resources should take this, as well as the motivation of educators to provide good education, as starting ground.

Although Dutch government has formulated ambitions on open sharing and reuse of learning materials and on MOOCs, in this study it was found that government's policy has not led to a broader adoption of OER. Most educators and some of the managers are unaware of the existence of the policy and its ambitions. Although in our study we focused on institutions with self-reported activities on open sharing and reuse, an institutional policy on this was lacking in some institutions.

Whether or not existent, not at all educators are aware of institutional policies and/or the specific content of these policies. This finding illustrates that "policy levers act far above the chalk face" (Haywood, Connelly, Henderikx, Weller, \& Williams, 2014, p. 8) and that a cascade of policy actions are needed to reach the level of the educator. This is especially important, because many educators mention a clear policy on openness as a necessary boundary condition to take away uncertainties and secure necessary support and opportunities. This finding is also reported in Czerniewicz et al. (2017). 
To better analyze, compare and explain barriers and enablers in a study on OER adoption at three South African universities, Cox and Trotter (2017) developed the concept of the OER Pyramid. In essence, this pyramid contains six layers. From the bottom to the top, these layers are: access to infrastructure (including electricity), permission to use or create OER, awareness of OER, capacity (skills and/or support available), availability of OER for use or sharing, and volition to adopt OER (Cox \& Trotter, 2017). Underlying this pyramid is the view that volition to adopt OER is taking place when all the underlying layers are fulfilled (Cox \& Trotter, 2017). For the Dutch Higher Education institutions, the barriers we found that prevent volition to adopt OER are mainly in the permission (educators are uncertain about it), awareness, and capacity layers. Access to infrastructure is no barrier at all, and the availability of OER for use and sharing was not mentioned. The latter resulted potentially from the fact that we used the opinions of the interviewees regarding what they called "open," which creates a larger set of potentially useful learning materials than the strict set of OER.

Our goal was to interview educators, and related actors, who were involved in open sharing and reusing of learning materials already, who we consider the principal actors in this innovation. It proved that not all interviewees were early adopters, but all were related to early adopters in their configurations. For a broader diffusion of the innovation, the educators who have adopted the innovation already, and their subjective evaluations, are of crucial importance. In institutional policy these near-peers can be regarded as social role models ("champions"), whose innovation behavior, according to Rogers' (2003) theory, hopefully will be imitated by others in their system.

Rogers (2003) has formulated generic recommendations to promote adoption of innovation. Applying these onto the findings from the interviews, the following recommendations at institutional level can be formulated.

\section{Recommendation 1}

Make the innovative features of open sharing and reuse clear to educators. Examples of such innovative attributes mentioned in the interviews are: improving quality of learning materials through review activities by peers, enhanced opportunities to connect with the outside world in education, enhanced opportunities to realize more personalized education, and opportunities to connect with peers when learning materials are shared and jointly developed. Make sure educators recognize the opportunities of open sharing and reuse. Make use of champions, inside or outside the institution, and sharing of good practices. Points of attention and opportunities in this regard are:

- Connect the innovative features of open sharing and reuse to the demands of the educator for providing good education to make clear the what's in it for me;

- Publishing a MOOC (regardless of subject) can be used to boost open sharing and reuse;

- Respect good practices regarding less open sharing and reuse by educators, as long as they do not suffer any damage (for example, violation of copyright rules). These practices may serve as a starting point for a teacher's behavioral change.

\section{Recommendation 2}

When changing the mindset of educators on open sharing and reuse as described under recommendation 1, organize adequate support for ICT, legal and educational aspects, make sure 
sufficient time is available, create a safe space for experimentation and implement an adequate infrastructure.

\section{Recommendation 3}

Formulate an institutional and faculty policy on open sharing and reuse to enable and secure the activities mentioned under recommendations 1 and 2. Connect this policy to broader educational innovations such as transition to blended learning or enhancing customization of education for individual learners. Translate these policies to influences on quality of education in the daily educational practices for the educator.

When following these recommendations, a point of attention is worth mentioning. One of the most commonly used mechanisms to introduce an innovation in an institution is to install a committee, in which all relevant categories of actors are represented. According to Dastur (2017), it is very likely that this approach will not lead to broader adoption, but on the contrary it may very like be counterproductive. Together laggards and late majority adopters comprise $50 \%$ of the institution's population, and most likely this coalition of the unwilling will slow down or even stifle the 'bright new idea' of adopting the sharing and reuse of open resources (Dastur, 2017). Therefore, following Dastur, a better strategy is to populate committees with innovators and early adopters, since the theoretical model of Rogers (2003) "predicts that if a committee is strategically populated with innovators and early adopters, then there is a better chance for an innovation to be diffused through the entire group" (Dastur, 2017, p. 172).

\section{Limitations of This Study}

In this explorative study our findings and conclusions are about sharing and reuse of OER and open online courses by educators, not about open education and/or educational technologies in general. Furthermore, it was an explorative qualitative study in which we have described and interpreted a variety of practices of sharing and reuse of open learning materials and online courses by faculty and staff in 10 Dutch public Higher Education institutions. Although most of our findings are confirmed by similar studies, more research is needed to support these findings before they can be generalized to all institutions of Higher Education in the Netherlands.

\section{Conclusions}

Our study has indicated that the actual rate of adoption of open sharing and reuse of learning materials and courses in publicly funded institutions of Higher Education in the Netherlands is rather low in terms of educators involved. The concepts of diffusion of innovation (Rogers, 2002, 2003) and configuration (Elias, 1978) have provided a structure for both the interview scheme and structuring of the recommendations. Compared to similar studies on adoption that used the survey as method for data collection, some findings are different. This can be attributed to the issue of self-reporting in similar (survey) studies and the many interpretations of "open" a participant has.

Whether our findings apply to all other Dutch Higher Education institutions, and thus to the Dutch public Higher Education system, has to be established in further research. It is our contention that this study has provided the appropriate information and concepts. Hopefully, implementation of the 
recommendations and the monitoring of their in and through institutions will lead to more detailed approaches, and to further adoption of sharing and reuse of open learning resources.

\section{Acknowledgements}

This research was partly funded by a grant from SURF Foundation. We thank the anonymous reviewers of a previous version for their comments, enabling us to improve the paper significantly. 


\section{References}

Aldoobie, N. (2015). ADDIE model. American International Journal of Contemporary Research, 5(6), 68-72. Retrieved from

http://www.aijcrnet.com/journals/Vol 5_No_6_December_2015/10.pdf

Allen, I., \& Seaman, J. (2016). Opening the textbook: Educational resources in U.S. higher education, 2015-16. Thornhill: Babson Survey Research Group. Retrieved from https://www.onlinelearningsurvey.com/reports/openingthetextbook2016.pdf

Belikov, O., \& Bodily, R. (2016). Incentives and barriers to OER adoption: A qualitative analysis of faculty perceptions. Open Praxis, 8(3), 235-246.

http://dx.doi.org/10.5944/openpraxis.8.3.308

Bliss, T. J., Robinson, T., Hilton, J., \& Wiley, D. (2013). An OER COUP: College teacher and student perceptions of open educational resources. Journal of Interactive Media in Education. 2013(1). http://doi.org/10.5334/2013-04

Boeije, H. (2008). Analyseren in kwalitatief onderzoek. Denken en doen. Amsterdam: Boom Lemma uitgevers.

Brennan, J., Ryan, S., Ranga, M., Broek, S., Durazzi, N., \& Kamphuis, B. (2014). Study on innovation in higher education: Final report. LSE Research Online. Luxembourg: Publications Office of the European Union. Retrieved from http://eprints.lse.ac.uk/55819/

Bryman, A. (2008). Social research methods (3rd ed.). Oxford, UK: Oxford University Press.

Cox, G., \& Trotter, H. (2017). Factors shaping lecturers' adoption of OER at three South African universities. In C. Hodgkinson-Williams \& P. B. Arinto (Eds.), Adoption and impact of OER in the Global South (pp. 287-347). https://doi.org/10.5281/zenodo.601935

Czerniewicz, L., Deacon, A., Walji, S., \& Glover, M. (2017). OER in and as MOOCs. In C. HodgkinsonWilliams \& P. B. Arinto (Eds.), Adoption and impact of OER in the Global South (pp. 349386). https://doi.org/10.5281/zenodo.604414

Dastur, F. (2017). How to open an academic department. In R.S. Jhangiani \& R. Biswas-Diener (Eds.), Open: The philosophy and practices that are revolutionizing education and science (pp. 163-178). London: Ubiquity Press. https://doi.org/10.5334/bbc.m

de los Arcos, B., Cannell, P., \& McIlwhan, R. (2016). Awareness of open educational resources (OER) and open educational practice (OEP) in Scottish higher education institutions. OEPS Interim Report. Retrieved from https://www.slideshare.net/OEPScotland/awareness-of-oer-and-oepin-scottish-higher-education-institutions-survey-results

de los Arcos, B., Farrow, R., Pitt, R., Perryman, L-A., Weller, M., \& McAndrew, P. (2015). OER research hub data 2013-2015: Educators. OER Research Hub. Retrieved from http://oro.open.ac.uk/47931/

Elias, N. (1978). What is sociology? London: Hutchinson. 
Elias, N., \& Dunning, E. (1990). Quest for excitement. Sport and leisure in the civilizing process. Oxford: Basil Blackwell.

Giddens, A. (1984). The constitution of society. Berkeley: University of California Press.

Hall, B. (2005). Innovation and diffusion. In J. Fagerberg, D. Mowery, \& R. Nelson (Eds.), Handbook on innovation (pp. 459-485). Oxford: Oxford University Press.

Haywood, J., Connelly, L., Henderikx, P., Weller, M., \& Williams, K. (2014). The changing pedagogical landscape. Luxembourg: Publications Office of the European Union. doi:10.2766/72063

Iizuka, M. (2013). Innovation systems framework: Still useful in the new global context? (United Nations University Working Paper Series No. 2013-005). Maastricht: UNU-MERIT

Jansen, D., Schuwer, R., Teixeira, A., \& Aydin, C. (2015). Comparing MOOC adoption strategies in Europe: Results from the HOME project survey. The International Review of Research in Open and Distributed Learning, 16(6), 116-136. http://dx.doi.org/10.19173/irrodl.v16i6.2154

Jhangiani, R. S., Pitt, R., Hendricks, C., Key, J., \& Lalonde, C. (2016). Exploring faculty use of open educational resources at British Columbia post-secondary institutions. BCcampus Research Report. Victoria, BC: BCcampus.

Ministry of Education, Culture and Science. (2015). The value of knowledge. Strategic agenda for higher education and research 2015-2025. Retrieved from https://www.government.nl/documents/reports/2015/07/01/the-value-of-knowledge

Mishra, S. (2017). Open educational resources: Removing barriers from within. Distance Education, 38(3), 369-380. doi:10.1080/01587919.2017.1369350

Nardi, B. (1996). Studying context: A comparison of activity theory, situated action models, and distributed cognition. In B. Nardi (Ed.), Contextual consciousness: activity-theory and human-computer interaction (pp. 69-102). Cambridge, IL: MIT Press.

OECD. (2014). Measuring Innovation in Education: A New Perspective. Educational research and Innovation Report. OECD Publishing. http://dx.doi.org/10.1787/9789264215696-en

Phalachandra, B., \& Abeywardena, I. S. (2016). Open educational resources in the commonwealth 2016. Burnaby, Canada: Commonwealth of Learning. Retrieved from http://hdl.handle.net/11599/2441

Richter, T., \& Ehlers, U. (2010). Barriers and motivators for using open educational resources in schools. In Open ED 2010 Proceedings (pp. 417-428). Barcelona: UOC, OU, BYU. Retrieved from http://hdl.handle.net/10609/4868

Rogers, E. M. (2002). Diffusion of preventive innovations. Addictive Behaviors, 27(6), 989-993. https://doi.org/10.1016/So306-4603(02)00300-3

Rogers, E. M. (2003). Diffusion of innovations (5th ed.). New York, NY: Free Press. 
Rolfe, V. (2017). Striving toward openness: But what do we really mean? The International Review of Research in Open and Distributed Learning, 18(7), 75-88. http://dx.doi.org/10.19173/irrodl.v18i7.3207

Schuwer, R., \& Janssen, B. (2016). Open educational resources en MOOC's in het Nederlandse Hoger Onderwijs. Eindhoven: Fontys Hogeschool ICT. Retrieved from http://bit.ly/oermoocnl2016

Schuwer, R., Wilson, T., Van Valkenburg, W., \& Lane, A. (2010). Production of OER, a quest for efficiency. In Open Ed 2010. Barcelona: UOC, OU, BYU. Retrieved from http://hdl.handle.net/10609/5103

Sloep, P. B., \& Jochems, W. (2007). De e-lerende burger. In J. de Haan \& J. Steyaert (Eds.), Jaarboek ICT en samenleving 2007; Eindelijk digitaal (pp. 171-187). Amsterdam: Boom

Truyen, F., Van Dorp, K., Janssen, B., Rivera, J., Griset, R., \& Kuppens, A. (2011). Open educational resources in a multi-campus and virtual campus environment. Proceedings of EDULEARN11 Conference, Barcelona, Spain, 1248-1258.

UNESCO / Commonwealth of Learning. (2012). 2012 Paris OER declaration. Retrieved from http://www.unesco.org/new/fileadmin/MULTIMEDIA/HQ/CI/CI/pdf/Events/English_Pari s OER Declaration.pdf

van Valkenburg, W., Kos, T., \& Ouwehand, M. (2015). MOOCs as accelerator of change. In D. Jansen \& A. Teixeira (Eds), Position papers for European cooperation on MOOCs (pp 19-24). Maastricht: EADTU. Retrieved from http://home.eadtu.eu/images/Position_papers_for_European cooperation_on_MOOCs.pdf

Weller, M. (2014). The battle for open: How openness won and why it doesn't feel like victory. London: Ubiquity Press. http://dx.doi.org/10.5334/bam

Weller, M., de los Arcos, B., Farrow, R., Pitt, B., \& McAndrew, P. (2015). The impact of OER on teaching and learning practice. Open Praxis, 7(4), 351-361. http://dx.doi.org/10.5944/openpraxis.7.4.22

Wilson, G., \& Stacey, E. (2004). Online interaction impacts on learning: Teaching the teachers to teach online. Australasian Journal of Educational Technology, 2o(1), 33-48. Retrieved from https://ajet.org.au/index.php/AJET/article/view/1366/736

\footnotetext{
i https://www.onderwijsincijfers.nl/kengetallen/hoger-beroepsonderwijs/deelnemers-hbo/ingeschreven-hogerberoepsonderwijs; https://www.onderwijsincijfers.nl/kengetallen/wetenschappelijkonderwijs/deelnemerswo/ingeschrevenen-in-het-wetenschappelijk-onderwijs

ii http://www.onderwijsincijfers.nl/kengetallen/hoger-beroepsonderwijs/personeelhbo/personeelssterkte; https://www.onderwijsincijfers.nl/kengetallen/wetenschappelijk-onderwijs/personeelwo/personeelssterkte
} 
Athabasca

University

(c) (1) 